DIW BERLIN

Discussion

Papers

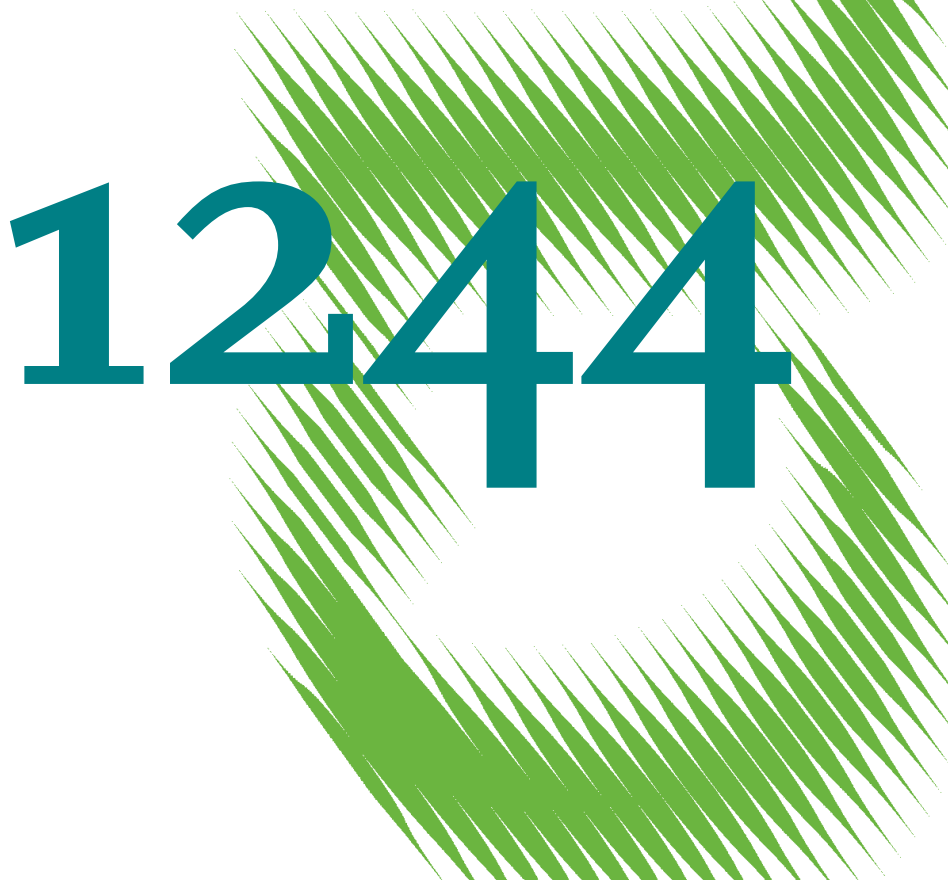

Noise Expectation and House Prices 
Opinions expressed in this paper are those of the author(s) and do not necessarily reflect views of the institute.

IMPRESSUM

(C) DIW Berlin, 2012

DIW Berlin

German Institute for Economic Research

Mohrenstr. 58

10117 Berlin

Tel. $+49(30) 89789-0$

Fax +49 (30) $89789-200$

http://www.diw.de

ISSN print edition $1433-0210$

ISSN electronic edition 1619-4535

Papers can be downloaded free of charge from the DIW Berlin website:

http://www.diw.de/discussionpapers

Discussion Papers of DIW Berlin are indexed in RePEc and SSRN:

http://ideas.repec.org/s/diw/diwwpp.html

http://www.ssrn.com/link/DIW-Berlin-German-Inst-Econ-Res.html 


\title{
Noise Expectation and House Prices
}

\author{
Andreas Mense* Konstantin A. Kholodilin ${ }^{\S}$
}

September 8, 2012

\begin{abstract}
In this paper, we examine the effects of an airport expansion on the prices of houses and flats located under the planned flight corridors. We focus on the role of expectations about the exposure to noise and find that proximity to the planned corridors significantly reduces real estate prices in the affected areas, by at least $28 \%$, depending on the sample. Hereby, the various plans of expanding Berlin-Brandenburg International airport are used as a source of exogenous variation.
\end{abstract}

Keywords: Airport noise, housing prices, price expectations, quasi-experiment, spatial effects.

JEL classification: C21; L93; R31.

\footnotetext{
*Friedrich-Alexander-Universität Erlangen-Nürnberg, Kochstraße 4, 91054 Erlangen, Germany, e-mail: Andreas. Mense@wiwi.phil. uni-erlangen.de

$\S$ DIW Berlin, Mohrenstraße 58, 10117 Berlin, Germany, e-mail: kkholodilin@diw.de
} 


\section{Introduction}

Noise is an important disutility negatively affecting the prices of housing, especially when it exceeds certain thresholds. Particularly annoying can be the noise produced by starting and landing airplanes. This is the reasoning that led the government of Berlin to undertake the construction of a new large airport at the southeastern outskirts of Berlin, whose opening would allow a radical change in the flight corridors in order to substantially reduce the noise exposure of Berlin. The process of planning the flight routes of the new airport was difficult and lengthy due to its utmost importance for the general public.

In August 2004, the Planungsfeststellungsbehörde, a regional planning unit, announced the decision to establish a single airport for Berlin and Brandenburg in Schönefeld ${ }^{1}$. In September 2010, the Deutsche Flugsicherung (DFS) presented preliminary flight corridors for BER to the public, including approximate climb gradients and average utilization of the routes. Due to heavy protests and after the formation of an expert committee on flight noise (Fluglärmkommission), the DFS updated the corridors in July 2011. Albeit the new corridors were again labeled as preliminary, certainty increased considerably. Final corridors were announced on January 26, 2012.

The impact of airport noise on house prices has been analyzed in a variety of articles. These studies were conducted mostly for the USA and Canada, but more recently also for some European airports. They rely on data of individual houses and regress prices on the exposure to noise (see Nelson (2004) for an overview). Cohen and Coughlin (2008) introduce spatial effects in a study of Atlanta airport in order to reduce omitted variable bias due to unobserved characteristics of the houses and their neighborhoods and use a three-regions noise band (no exposure, 65-70 dB, above $70 \mathrm{~dB}$ ) around the airport. Salvi (2007) conducts a similar exercise for Zurich airport, but uses a much denser noise coverage.

Boes and Nüesch (2011) use a change in flight regulations for Zurich airport that led to a new pattern of noise, and exploit the resulting variation. The quasi-experimental design lifts some weight off the hedonic regression in the empirical strategy since it is reasonable to assume that treatment, i.e., noise, was assigned randomly to a set of houses. In addition, their noise data are superior in terms of density and variation. Whereas most studies in the spirit of Cohen and Coughlin (2008) rely on noise contours with only one or two different regions that have relatively high cutoff values, the noise data of Boes and Nüesch are continuous and geographically precise.

\footnotetext{
${ }^{1}$ See http://www.mil.brandenburg.de/sixcms/detail.php/bb1.c.155589.de for details. Schönefeld is located just outside the south-eastern city limits of Berlin.
} 
However, the authors only consider rents and not property prices, which makes it difficult to compare their results with those of other studies. Moreover, they exclude observations ten months before and twelve months after the change, which is why their estimates are likely to cover long-term reactions, but not the adjustment process.

The airports of Berlin were examined in two studies by Ahlfeldt and Maennig (2007, 2011). The authors found little evidence for accessibility effects of airports, but substantial discounts of approximately $40 \%$ for residential property when noise exposure is above $55 \mathrm{~dB}$. They also identify a nonlinearity at $55 \mathrm{~dB}$, above which most of the noise discount sets in. The authors note the importance of controlling for accessibility effects in order to prevent a bias of the estimated noise discount.

The focus of this study is different in two ways. First of all, the planning stage of Berlin-Brandenburg International (BER) airport located in Schönefeld, south of Berlin, allows us conducting a quasi-experiment, since the proposed flight routes changed considerably from the first sketch (September 2010) to an intermediate stage (July 2011) and the announcement of the final air corridors (January 2012) ${ }^{2}$. Secondly, noise only plays an indirect role in this setup, since it is the anticipated noise that drives prices here. We attempt to measure the price decline that is due to the announcment of the flight corridors. Thereby, we draw attention to the adjustment process and the potential harm that might result from a disruptive planning stage. We also circumvent common problems related to the modeling of noise exposure, since we rely solely on planned flight routes.

\section{Data and empirical approach}

\subsection{Data}

The real estate data come from three online real estate advertising websites, Immobilienscout24 (IS24), Immonet, and Immowelt ${ }^{3}$. Up to April 2011, the only source available to the authors is IS24. The data were provided by IS24 directly and free of charge thanks to a cooperation agreement concluded between the authors and Immobilienscout24.

Only those observations were used for which the exact address and coordinates were known. The data also

\footnotetext{
${ }^{2}$ Unfortunately, our data do not allow examining prices before the decision for the expansion was settled in the first place.

${ }^{3}$ For details on the data, the reader is referred to Kholodilin and Mense (2011).
} 
contain control cases that are situated in Berlin and south Brandenburg, but are not close to a corridor at any point in time. This enables us to shed some light on the reaction of house prices during the planning stages of the construction of an airport by conditioning on price changes in and around Berlin that are not related to BER. This paper is concerned with expectations about aircraft noise, not actual noise levels. Therefore, we make use of the coordinates of the planned flight corridors. OLS regression is applied to account for quality differences between houses and obtain the separate price effect caused by the announcement only.

In addition, several geographical and amenity variables were collected from various sources in order to take into accout the effect of location upon the housing prices.

The coordinates of the flight corridors were taken from the DFS web page. All data sources are summarized in table A.1.

\subsection{Price expectations and the planning stage}

The announcements of the flight routes for BER on September 27, 2010, and their updates on July 4, 2011, and January 26, 2012 may be seen as a quasi-experiment for examining the reaction of housing prices to expected flight noise. Part of this is the housing price adjustment that potentially took place between August 2004 and the first announcement in September 2010. Unfortunately, our data do not permit addressing this issue. However, we might still be able to examine the reactions to the announcements of the corridors. As will be laid out below, the different planning stages enable us to work around this problem to a certain extent. In the present setup, we use data from April to June 2011 and August to October 2011.

If price effects occurred before September 2010 for locations that were affected finally, a solution would be to control for these anticipation effects. In case the anticipated price drop is not controlled for, the estimated price decline will be too small because of the reduced price in the base period.

In order to further reduce the anticipation effect we make use of the three announcements in the following way: In September 2010, the situation was relatively hard to grasp. People might have reacted ex ante or they might have not. Due to the news, however, expectations were "settled" and people adjusted their expectations. Those unaffected in 2010 most definitely placed a lower probability on the event of treatment. As a consequence, the estimates for this group will be biased by anticipation effects to a much smaller degree. 
Therefore, the update of the corridors in July 2011 (J11) was used as a source of exogenous variation. We make use of the fact that people reacted to the first announcement in September 2010 (S10). It is therefore reasonable to assume that people unaffected in September 2010 expected to be affected by the final plans with a much smaller probability.

\subsection{Empirical specification}

Our econometric model can be formulated as follows:

$$
Y_{i}=\mathbf{X}_{\mathbf{i}} \beta+\left[\begin{array}{lll}
A_{i} & D_{i} & G_{i}
\end{array}\right] \gamma+\left[A_{i} \times G_{i}\right] \theta+\left[A_{i} \times D_{i}\right] \delta+\varepsilon_{i}
$$

where $Y_{i}$ is the price per square meter, $\mathbf{X}_{\mathbf{i}}$ is a vector of control variables, including house or apartment type, the square area of the apartment, the number of rooms, the site area, dummies for presence of a balcony or a terrace, a parking lot, a fitted kitchen, an elevator, a garden, and a second bathroom, as well as for the requirement of a commission payment. Year of construction is controlled for via a set of dummies for seven housing age groups (including the category "new"). Additional dummies indicate whether the dwelling is rented out, and whether it is suitable for the elderly and for handicapped persons. The number of ads within $500 \mathrm{~m}$ from the observation was used as a proxy for population density. This variable was also interacted with other covariates to capture higher prices caused by the scarcity of space in densely populated areas. In addition, some location variables were introduced. These include the distance to the next train station, Autobahn, Bundesstraße (national highway), kindergarten, restaurant, supermarket, lake, park, BER, and to the city centers of Berlin and Potsdam ${ }^{4}$. Throughout the paper, we denote distance variables by "d.variable_name".

$D_{i}$ is a vector that contains the distance to the next corridor and the distance to BER. It turned out that cutting the distance to a corridor at $4.5 \mathrm{~km}$ leads to reasonable results, although the cutoff was not necessary ${ }^{5}$. Both log and linear forms of distance were used, but yielded similar results. In what follows, we therefore only report the linear results.

$A_{i}$ is the announcement dummy, which is equal to 1 for ads published after the announcement and 0

\footnotetext{
${ }^{4}$ These were used as approximations to the central business districts (CBD). For Berlin, we used the estimate of Ahlfeldt and Maennig (2011)

${ }^{5}$ For $x$, values from $3.0 \mathrm{~km}$ to $6.0 \mathrm{~km}$ were tested in steps of $100 \mathrm{~m}$, and $4.5 \mathrm{~km}$ was chosen as the cutoff value. Thus, for distances greater than $4.5 \mathrm{~km}$, the value was set to 4.5 .
} 
otherwise. It is the interaction of the announcement dummy with $D_{i}$ that is the focal point of the analysis: The combination of $A_{i}$ and the distance to a corridor captures the effect of the announcement on the treatment group. We expect a drop in the price per square meter due to the negative effect of noise on the value of a location. $A_{i} \times d . B E R$ controls changes in the assessment of airport proximity due to the announcement. These might be due to job accessibility effects, but may also catch anticipation effects. The identification of the announcement effect requires to account for time trends in the sample as well as local time trends that might differ substantially since we attempt to use observations from Berlin, for which prices increased sharply in 2011 (see, e.g. Kholodilin and Mense (2012)) and Brandenburg. The interaction of $A_{i}$ and $G_{i}$ is designed to catch these trends. For $G_{i}$, a full set of ZIP code dummies were used.

In addition, we present results from a spatial lag model (SLM) and a spatial error model (SEM). The first takes into account spatial dependencies between observations through regressing the own price on the price of neighboring houses. The latter introduces a spatially correlated error term that also attempts to take into account unexplained variation that can be attributed to the location of the building. The spatial lag model (SLM) has the following form:

$$
Y_{i}=\rho W_{i} Y+\mathbf{X}_{\mathbf{i}} \beta+\left[\begin{array}{lll}
A_{i} & D_{i} & G_{i}
\end{array}\right] \gamma+\left[A_{i} \times G_{i}\right] \theta+\left[A_{i} \times D_{i}\right] \delta+\varepsilon_{i}
$$

where $\rho$ is the spatial lag coefficient and $W_{i}$ is a normalized weight vector with weights $w_{i, j}=\frac{1}{d_{i, j}}$ where $d_{i, j}$ the distance of $i$ to the $j$ th-nearest neighbor. Only the $K=5$ nearest neighbors are used, such that $\forall j>K: w_{i, j}=0$. The model is estimated by the maximum likelihood method. Similarly, the spatial error model (SEM) is defined as:

$$
Y_{i}=\mathbf{X}_{\mathbf{i}} \beta+\left[\begin{array}{lll}
A_{i} & D_{i} & G_{i}
\end{array}\right] \gamma+\left[A_{i} \times G_{i}\right] \theta+\left[A_{i} \times D_{i}\right] \delta+u_{i}, \quad u_{i}=\lambda W_{i} u+\varepsilon_{i}
$$

where $\lambda$ is the spatial error coefficient. 


\section{Estimation results and discussion}

We assigned categories to the observations, conditional on their status as a) new under a corridor; b) under a corridor that was confirmed; or c) not under a corridor anymore see Figure A.1. An observation was considered to be under a corridor at a point in time if its distance was less than $4.5 \mathrm{~km}$. Control observations with distances between 4.5 and $25 \mathrm{~km}$ from any corridor were included in all specifications. The distance difference (d.S10d.J11) was introduced in order to capture the effect of relative distance changes for group c) ${ }^{6}$. Its coefficient is expected to have a negative sign since a relatively smaller J11 distance should exert downward pressure on prices.

Table 1: July 2011 - OLS estimation results

\begin{tabular}{|c|c|c|c|}
\hline & \multicolumn{3}{|c|}{ Group } \\
\hline & a) & b) & c) \\
\hline d. $. J 11_{4.5} \times A$ & $\begin{array}{c}187.0^{* * *} \\
(62.8)\end{array}$ & $\begin{array}{c}126.8^{* *} \\
(57.6)\end{array}$ & - \\
\hline$($ d.S10-d.J11) $\times A$ & - & - & $\begin{array}{c}-54.6^{* * *} \\
(19.7)\end{array}$ \\
\hline d.J11 $11_{4.5}$ & $\begin{array}{l}-44.8 \\
(41.8)\end{array}$ & $\begin{array}{c}-63.3^{*} \\
(38.4)\end{array}$ & - \\
\hline d. $B E R \times A$ & $\begin{array}{c}-47.1^{* * *} \\
(10.7)\end{array}$ & $\begin{array}{c}-32.8^{* * *} \\
(11.8)\end{array}$ & $\begin{array}{c}-33.3^{* * *} \\
(12.3)\end{array}$ \\
\hline d.BER & $\begin{array}{c}35.0^{* * *} \\
(9.7)\end{array}$ & $\begin{array}{c}38.3^{* * *} \\
(10.2)\end{array}$ & $\begin{array}{c}30.9^{* * *} \\
(10.5)\end{array}$ \\
\hline$R^{2}$ & 0.684 & 0.683 & 0.694 \\
\hline Adjusted $R^{2}$ & 0.661 & 0.660 & 0.673 \\
\hline Observations & 6132 & 6137 & 6267 \\
\hline \multicolumn{4}{|c|}{$\begin{array}{l}\text { Dependent variable is price per square meter, heteroscedasticity-corrected standard errors are in } \\
\text { parentheses. The subscript } 4.5 \text { indicates a cutoff at } 4.5 \mathrm{~km} \text {. The distance difference variable (d.S10- } \\
\text { d.J11) } \times A \text { is the difference between S10 and J11 distances and set to } 0 \text { for observations more than } \\
4.5 \mathrm{~km} \text { from all J11 and S10 corridors. In all cases, the sample is restricted to observations that are } \\
\text { located more than } 5.0 \mathrm{~km} \text { from the airport and the city center and belong to ZIP codes } 12000-15999 \text {. } \\
\text { The complete list of covariates can be found in table A.2. } \\
\text { p-values: } * * *:<0.01, * *:<0.05, *:<0.10 \text {. }\end{array}$} \\
\hline
\end{tabular}

Table 1 reports the estimates for the July 2012 plans. The main effect for the interaction of the distance to a corridor with the announcement dummy is highly significant for group a). In terms of its magnitude, it predicts a 187.0 euros decline per $\mathrm{km}$ within the first $4.5 \mathrm{~km}^{7}$ : A house located at more than $4.5 \mathrm{~km}$ direct air distance to a corridor would have its square meter price reduced by around 561 euros when moving to a place at $1.5 \mathrm{~km}$

\footnotetext{
${ }^{6}$ The variable was set to 0 for all observations belonging to the control group.

${ }^{7}$ The minimum distance in the sample is $1.3 \mathrm{k} \mathrm{m}$, which is why inference should not be drawn for extreme cases here. It is likely that the effect does not increase any further beyond some point at which the noise exposure has reached a certain level. For example, Boes and Nüesch (2011) estimate an S-shaped curve that flattens out above 45-50 dB(A).
} 
distance, which amounts to a noise-related decrease of the mean price in that area by $38 \%$. When using the results from the hedonic regression to construct a representative house and a representative appartment (where all variables were set to the mean or median value of the affected houses or appartments), the relative price decrease is $27 \%$.

The decline of 126.8 euros per $\mathrm{km}$ for group b) is much smaller and significant only at the $5 \%$-level. Other specifications (not reported here) showed that the coefficient was not very robust to changes in the model. This is perfectly in line with expectations since the plans did not hold as much information for group b) as they did for groups a) and c).

To capture the effect of a relative distance change for group c), the variable (d.S10-d.J11) was defined as the difference in distance to the S10 and the J11 corridors. Thus, for a smaller S10 distance, its sign is negative and a price increase would be expected (and vice versa). Group c) experienced a price increase of 54.6 euros per $\mathrm{km}$ of difference in distance when starting at a location less than $4.5 \mathrm{~km}$ from a S10 corridor. It must be noted, however, that this coefficient was also not as stable as the coefficients for group a) when using alternative specifications. Together, the results for group b) and c) indicate that most of the reaction took place in July 2011, whereas the implied effect in September 2010 was modest. When adding up the effects for groups c) and b), the total effect is again in the range of the estimate for group a).

In all three cases, the d.BER variable has a positive impact on prices which is offset by the announcement. This means that at greater distances, the price was higher ceteris paribus, but only until the plans were known publicly. At this point, uncertainty was reduced such that locations close to the airport, but not to a corridor did not sell at a discount as compared to locations farther away from the airport. We interpret this as an anticipation effect: House prices were lower around the airport due to the uncertainty about flight corridors. In other words, d.BER served as a predictor for corridor proximity. Thus, given the size of the noise effect and the behavior of the d.BER coefficients, we do not believe that the anticipation of a price decline introduced much bias into the results.

One other coefficient deserves mentioning here: The negative estimate for the distance to a J11 corridor (without interaction) is counterintuitive since it implies higher, not lower prices around the J11 corridors that were in place already before the announcement. We believe this is attributable to omitted variable bias. It must 
be noted that the results for group a) that are key in the present setup are not affected by this result: Due to the fact that they rely on the exogenous variation induced by the publication of the new plans in July 2011, we are confident that these estimates capture relatively well the price decline that is due to the expecation of aircraft noise.

As a short robustness check, a full model for group a) is also reported in Table A.2, including a list of all covariates that were used for the models in Table 1. In order to investigate the effect of the distance difference for group a), we added this variable to the model. In contrast to the model in column a) of Table 1, all observations within 4.5 and $15 \mathrm{~km}$ distance to a corridor were excluded to reduce bias through anticipation effects. The idea is that "endangered" sellers who did not end up under a corridor as of July 2011 react by a price increase. If these observations belong to the control group, the estimate is biased upwards. The results do not suggest this outcome: The coefficient on the distance variable gets slightly bigger. In addition, the distance difference variable is marginally significant, indicating an even stronger effect when the S10 corridor was relatively far away. In the spatial lag and the spatial error model, both coefficients increase in magnitude, and the distance difference variable becomes significant at the $5 \%$ level.

The variables capturing the quality of the apartment or house all have the desired sign, although the coefficients for "Use of garden" and "suited for the elderly" are insignificant. The same holds for the categorial variables "Quality", "Level", "Condition" and "Year of construction". Higher distance to Berlin and to Potsdam reduces prices significantly, as well as a higher distance to the next park or lake or national highway (Bundesstraße). The coefficients for the distance to the next train station and to the next kindergarten are of the correct sign, but insignificant. The latter is also true for the distance to the next Autobahn, which seems to have a rather positive impact, probably due to noise and other disamenities related to traffic. Finally, a higher number of ads in the neighborhood of the observation reduces the price significantly. Most coefficients are stable when comparing the OLS to the SLM and SEM, whereby the SLM has the lowest AIC value. Also, the spatial lag coefficient, $\rho$, and the spatial error coefficient, $\lambda$, are highly significant.

Taken as a whole, these figures show that airport noise is extremely costly for house owners. We find that the square meter price of residential property declined by around $13 \%$ per $\mathrm{km}$ direct air distance to a corridor in-between a range of 1.3 to $4.5 \mathrm{~km}$ according to the results in table 1 . What is new about this result is the 
fact that the variation in the data is driven by the announcement of new flight corridors for BER and not by the already existing noise. Earlier results did not build upon such a quasi-experimental setup. Secondly, these estimates rely on the expectation of noise: House sellers and buyers seem to react to the publication of new flight corridors within days. Following up on this study, the price dynamics affected by the actual noise level that will be experienced after the airport starts to operate could indicate whether people estimated the level of noise exposure correctly, i.e., whether prices will essentially remain stable or not.

To summarize, the findings stress the importance of a transparent planning stage for the expansion of airports. They also make clear that locating airports in close proximity to densely populated areas might destroy considerable parts of the wealth of the inhabitants. From an economic point of view, these effects represent externalities which should be priced in accordingly.

\section{References}

Ahlfeldt, G. and W. Maennig (2007). Assessing External Effects of City Airports: Land Values in Berlin. Working Papers 011, University of Hamburg.

Ahlfeldt, G. M. and W. Maennig (2011). External productivity and utility effects of city airports. Technical Report http://eprints.lse.ac.uk/, London School of Economics and Political Science.

Boes, S. and S. Nüesch (2011). Quasi-experimental evidence on the effect of aircraft noise on apartment rents. Journal of Urban Economics 69(2), 196-204.

Cohen, J. P. and C. C. Coughlin (2008). Spatial Hedonic Models of Airport Noise, Proximity, and Housing Prices. Journal of Regional Science 48(5), 859-878.

Kholodilin, K. A. and A. Mense (2011). Can Internet Ads Serve as an Indicator of Homeownership Rates? Working Paper 1168, DIW Berlin.

Kholodilin, K. A. and A. Mense (2012). Internet-Based Hedonic Indices of Rents and Prices for Flats: Example of Berlin. Working Paper 1191, DIW Berlin. 
Nelson, J. P. (2004). Meta-Analysis of Airport Noise and Hedonic Property Values. Journal of Transport Economics and Policy 38(1), 1-28.

Salvi, M. (2007). Spatial Estimation of the Impact of Airport Noise on Residential Housing Prices. SSRN eLibrary. 


\section{Appendix}

Overview: July 2011

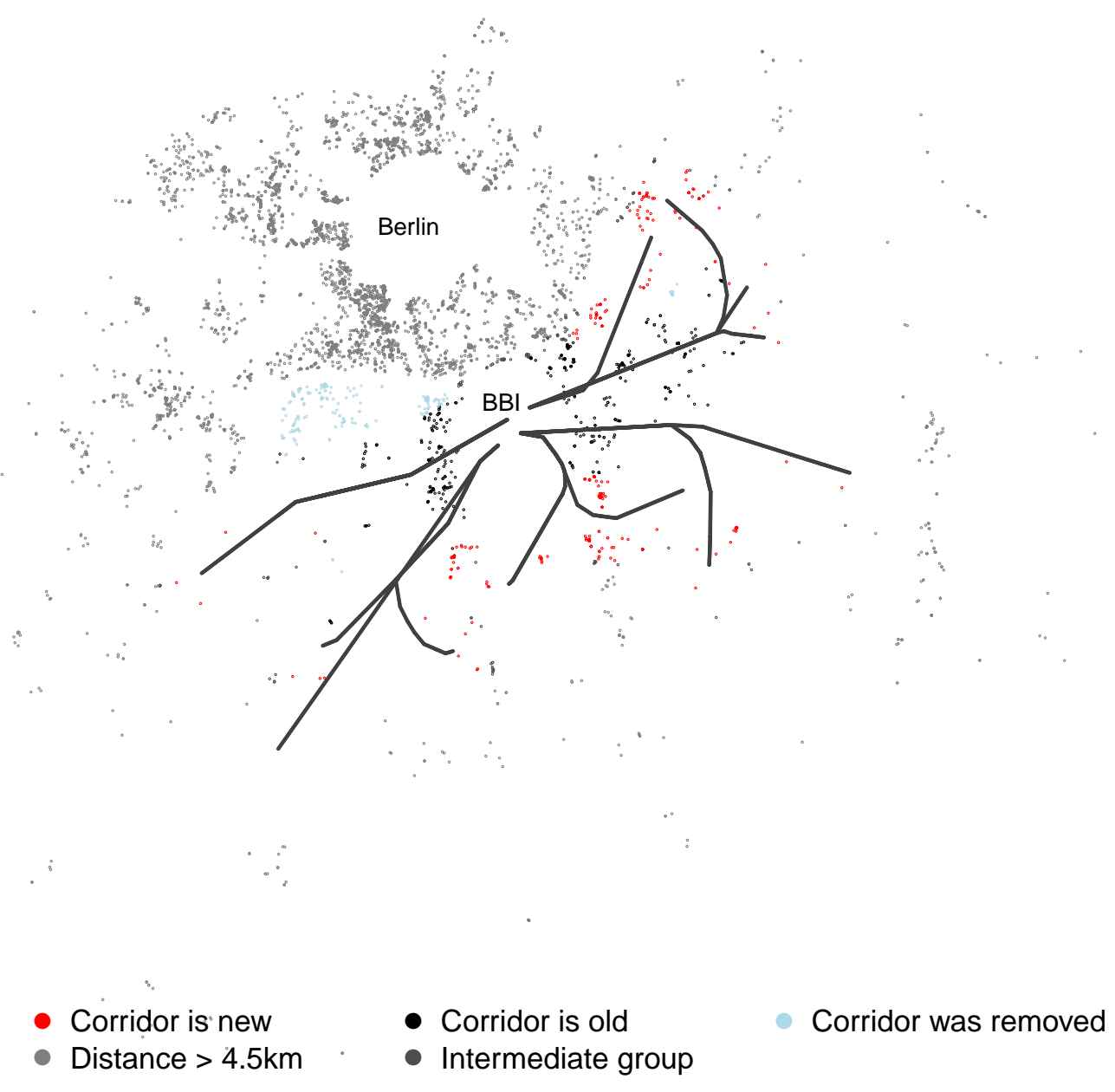

Figure A.1: Planned jet corridors for BER, July 2011 
Table A.1: Data sources

\begin{tabular}{ll}
\hline Variable & Source \\
\hline housing data & Immoscout24 (2007-2012), \\
& Immonet, Immowelt (04/2011-05/2012) \\
flight corridors & Deutsche Flugsicherung GmbH \\
train station, Autobahn, & Open Street Map project, \\
national highway, restaurant, & www.openstreetmap.org \\
park, lake & \\
kindergarten & Berliner Senatsverwaltung für Bildung, Jugend \\
& und Wissenschaft, \\
& www.berlin.de/sen/familie/kindertagesbetreuung/ \\
& kita_verzeichnis/anwendung/Index.aspx \\
& Landesjugendamt des Landes Brandenburg, \\
& www.lja-brandenburg.de/kita/index_kitas.php \\
& www.supermarktcheck.de/supermaerkte/ \\
google maps, maps.google.com
\end{tabular}


Table A.2: July 2011, new corridor

\begin{tabular}{|c|c|c|c|}
\hline & OLS & SLM & SEM \\
\hline Intercept & $2839.0^{* * *}$ & $2477.3^{* * *}$ & $2895.5^{* * *}$ \\
\hline d. $. J 11_{4.5} \times A$ & $201.3^{* *}$ & $216.0^{* * *}$ & $240.8^{* * *}$ \\
\hline$($ d.S10-d.J11) $\times A$ & $-88.1^{*}$ & $-97.0^{* *}$ & $-109.7^{* *}$ \\
\hline d..$J 11_{4.5}$ & -72.3 & $-78.6^{*}$ & $-98.8^{* *}$ \\
\hline (d.S10-d.J11) & -33.7 & -29.9 & -35.3 \\
\hline d. BER $\times A$ & $-77.1 * * *$ & $-74.2^{* * *}$ & $-73.6^{* * *}$ \\
\hline d.BER & $87.8^{* * *}$ & $83.1^{* * *}$ & $75.9 * * *$ \\
\hline Area & $-708.3^{* * *}$ & $-725.2^{* * *}$ & $-673.5^{* * *}$ \\
\hline Rooms & $467.1^{* * *}$ & $431.7^{* * *}$ & $376.6^{* * *}$ \\
\hline Lot size & $686.1^{* * *}$ & $684.6^{* * *}$ & $712.4^{* * *}$ \\
\hline Balcony & $91.1^{* * *}$ & $81.8^{* * *}$ & $74.6^{* * *}$ \\
\hline Use of garden & 28.1 & 24 & 34.2 \\
\hline Elevator & $161.5^{* * *}$ & $154.7^{* * *}$ & $163.1^{* * *}$ \\
\hline Rented out & $-87.1^{* * *}$ & $-77.4^{* * *}$ & $-75.7^{* * *}$ \\
\hline Suited for the elderly & 43.9 & 33.1 & 19.5 \\
\hline Parking lot & $33.3^{* * *}$ & $33.9 * * *$ & $31.2^{* * *}$ \\
\hline Commission & $-72^{* * *}$ & $-64.4^{* * *}$ & $-69.9 * * *$ \\
\hline \multicolumn{4}{|l|}{ Quality } \\
\hline simple & $-137.6^{* *}$ & $-118^{* *}$ & $-128.1^{* *}$ \\
\hline standard & $-71.5^{* * *}$ & $-70.4^{* * *}$ & $-64.3^{* * *}$ \\
\hline elevated & $139.7^{* * *}$ & $142.8^{* * *}$ & $150.3^{* * *}$ \\
\hline luxury & $249.1^{* *}$ & $289.3^{* * *}$ & $314.5^{* * *}$ \\
\hline \multicolumn{4}{|l|}{ Level } \\
\hline ground level & 20.1 & 5.9 & -5.4 \\
\hline $1-2$ & $95.1^{* * *}$ & $81.4^{* * *}$ & $67^{* *}$ \\
\hline $3-5$ & 31 & 22 & 8.7 \\
\hline $6+$ & -89.2 & $-100.9^{*}$ & $-96.2^{*}$ \\
\hline \multicolumn{4}{|l|}{ Condition } \\
\hline Old building & -26.5 & -33.4 & -32.3 \\
\hline first occupation & $192.3^{* * *}$ & $176.2^{* * *}$ & $176.3^{* * *}$ \\
\hline first occupation after refurbishment & $431.2^{* * *}$ & $385.8^{* * *}$ & $411.9^{* * *}$ \\
\hline refurbished & 1.4 & 14 & 39.6 \\
\hline mint condition & 25.8 & 21.9 & 32.9 \\
\hline renovated & -43.6 & -21.6 & 6.9 \\
\hline well-kept & 0.5 & 5.9 & 19.5 \\
\hline modernized & -53.9 & -63.9 & -35.7 \\
\hline in need of renov. & $-153.3^{* * *}$ & $-150.3^{* * *}$ & $-134.4^{* * *}$ \\
\hline \multicolumn{4}{|l|}{ Year of construction } \\
\hline $1900-1917$ & $-173.7^{* * *}$ & $-115.6^{* *}$ & $-113^{* *}$ \\
\hline $1918-1944$ & $-105.2^{* *}$ & -64.6 & $-83.7^{*}$ \\
\hline $1945-1988$ & $-234.3^{* * *}$ & $-177.7^{* * *}$ & $-193.8^{* * *}$ \\
\hline 1989-1997 & -39.1 & 14.5 & 19.9 \\
\hline 1998-2004 & 60.3 & $101.5^{* *}$ & $95.1^{*}$ \\
\hline $2005-2010$ & $154.6^{* * *}$ & $170.7^{* * *}$ & $201.4^{* * *}$ \\
\hline New & -41.2 & 2 & 13.9 \\
\hline
\end{tabular}


(table A.2 continued)

\begin{tabular}{|c|c|c|c|}
\hline \multicolumn{4}{|l|}{ Distances } \\
\hline d.Berlin & $-2249.6^{* *}$ & $-2051.2^{* *}$ & -1435.9 \\
\hline d.Potsdam & $-2301.6^{* * *}$ & $-2322.1^{* * *}$ & $-2418.1^{* * *}$ \\
\hline d.train_station & -598.6 & -482.4 & -568.2 \\
\hline d.supermarket & $905.4^{* * *}$ & $798.6^{* * *}$ & $881.9^{* * *}$ \\
\hline d.national_highway & $-278^{*}$ & $-347.1^{* *}$ & $-394.4^{* *}$ \\
\hline d.Autobahn & 445.3 & 419.1 & 485 \\
\hline d.kindergarten & -98.9 & -33.8 & -168.7 \\
\hline d.park & $-857.3^{* * *}$ & $-764.9^{* * *}$ & $-899.1^{* * *}$ \\
\hline d.lake & $-341.6^{*}$ & -221 & -233.3 \\
\hline pop. density & $-142.8^{* *}$ & $-146.1^{* *}$ & $-129.1^{*}$ \\
\hline \multicolumn{4}{|c|}{21 building type dummies } \\
\hline \multicolumn{4}{|l|}{93 ZIP code dummies } \\
\hline$\rho / \lambda$ & - & $0.215^{* * *}$ & $0.269^{* * *}$ \\
\hline Observations & 2476 & 2476 & 2476 \\
\hline Adjusted $\mathrm{R}^{2}$ & 0.627 & - & - \\
\hline $\mathrm{AIC}$ & 2110 & 2038 & 2058 \\
\hline \multicolumn{4}{|c|}{$\begin{array}{l}\text { Dependent variable is the price per square meter, OLS standard errors } \\
\text { are heteroskedasticity-corrected. Pop. density is the number of ads } \\
\text { within a distance of } 500 \mathrm{~m} \text {. All variables are scaled to }[0,1] \text {, except for } \\
\text { those reported also in Tables } 1 \text {. The selection of variables corresponds } \\
\text { to the one in Table } 1, \text { column }(1) \text {. } \\
\text { p-values: } * * *:<0.01, * *:<0.05, *:<0.10 \text {. }\end{array}$} \\
\hline
\end{tabular}

